\title{
Correction to: The Tokyo Medical University entrance exam scandal: lessons learned
}

\section{Greg Wheeler}

\author{
Correspondence: wheeler@sapmed. \\ ac.jp \\ The original article can be found \\ online at https://doi.org/10.1007/ \\ s40979-018-0039-4 \\ Sapporo Medical University, South \\ 1, West 17, Chuo-ku, Sapporo \\ 060-8556, Japan
}

\section{Correction to: Int J Educ Integr}

https://doi.org/10.1007/s40979-018-0039-4

Following publication of the original article (Wheeler 2018), the author attempted to provide an overview of a scandal occurring at a Japanese university over its practice of lowering the scores of (primarily) female applicants and offered possible suggestions as to how to prevent this from reoccurring. It was primarily an opinion piece on an ongoing issue, one that has caused great concern in Japanese academia. Since this is still a somewhat fluid situation, with new information often unfolding, the author would like here to provide a few updates to the original article. Moreover, he believes a number of the statements appearing in the original paper could have been stated more clearly and feels some amount of clarification is in order.

One matter that has caused confusion and requires an update concerns the sections of TMU's entrance exam in which the scores were lowered. Many of the early media reports indicated that the alterations occurred after the first phase of the admissions process, the written exam, and this is what the author reported as well. The author also suggested the possibility that gender bias might have played a role in the interviews, which along with written essays, comprised phase 2 of the exam process. (The author should note that the term "exam" includes both phase 1 and phase 2.) However, according to a report TMU has issued on its webpage, although a few applicants received extra points on phase 1 , the lowering of scores occurred mostly during phase 2 , but on the essays rather than the interviews (Tokyo Medical University 2018a). These essays were worth 100 points. It appears that all applicants' initial scores out of 100 were first multiplied by 0.8 . Subsequently, male first-time applicants had 20 points added to their scores. Those taking the test for the second or third time also had 20 points added and those trying for the fourth time had 10 points added. Female applicants and those trying for the fifth time had 0 points added. There is no indication, however, that interview scores were lowered and the author apologizes to both the readers and those conducting the interviews for suggesting that they may have.

Regarding the Ministry of Education's investigation into potential gender discrimination among the medical schools, one major development to date is that the Ministry has now named multiple schools it believes have likely engaged in inappropriate practices concerning their entrance exams (The Mainichi 2018). One of these schools includes Juntendo, which had previously denied that gender bias had played a role in its entrance exam process. The university has since acknowledged that it altered scores in favor of 
male applicants, suggesting that women tend to mature more quickly than men mentally, and the male applicants may therefore have needed extra assistance (Ma 2018).

Concerning the Ministry of Education's recommendation that universities make their exam problems and answers public (of note, the Ministry guidelines covered many topics concerning university admissions, not just entrance exam openness, and the clause "especially those that required examinees to write paragraphs or short essays" appearing in the paper was meant to provide examples of possible subjective questions, and was not stated directly by the Ministry), the author recently conducted an informal search of many university websites to examine whether such problems/answers were available. Although this search was not exhaustive and the results are by no means conclusive, it is his impression that the number of schools posting exam content has possibly increased. When conducting this search, it was still not common to find instances in which exam questions were included, but they did seem to appear more frequently than in the past. It was also rare to view explanations about or answers to the questions, but the author did find on occasion such instances. Whether this is in response to the Ministry of Education's suggestions is an issue worth exploring in the future. Moreover, although it is often true that applicants do not receive much in the way of information about their tests (many universities do not even send rejection notices to those who were not successful), at the author's university, there is a limited period in the spring during which all applicants can learn their exam scores if they are willing to visit the university's campus (Personal correspondence with Sapporo Medical University professor Shinji Kimura, 27 December 2018). It is possible that other universities may have a similar policy.

Finally, although TMU normally sets its admission target at 75 acceptances for those applying through the ippan nyüshi system, that number for 2019 has been lowered to 34 (Tokyo Medical University 2018b). This is perhaps due to its decision to accept many of the applicants who had been rejected during the 2017 and 2018 admissions process after their scores were altered. It also appears as if the number of 2019 applicants to the medical program at TMU has dropped considerably (The Sankei News 2019).

In addition to the updates, the author would like to clarify some statements from the original paper. Concerning the $j u k u$, for example, based on consultations the author has had with university members involved with the admissions process, the author suggested there was a possibility that some might buy copies of entrance exams from test-takers. It is, however, possible that one official may have been referring to companies reproducing the exams other than the juku and the author should have more clearly stated that he believes such purchases (by any private businesses reproducing the exams), if any, are rare. Also, although there may be university concerns over the reactions the juku might have to questions without definite clear answers (Dunn 2016, Guest 2008 and several conversations the author has had over the years with university faculty expressing trepidation about potential juku responses to "unorthodox" content that may appear on the exams), the evaluations that some post on their websites mostly analyze and offer strategies for answering the test questions and assess their difficulty levels. Although it may be possible that subtle criticisms appear in these evaluations, the author believes it unlikely that they would state directly that a test question is bad.

There are a few minor overstatements that appear in the paper that the author should also address. For example, although many graduates from the highly ranked high schools 
may enroll in medical universities, this does not necessarily mean that the high schools "steer" them toward these programs as suggested by the author. Additionally, when describing how $65 \%$ of female physicians noted they could understand TMU's stated reasons for lowering the entrance exams scores of female applicants, the author may have over interpreted some of the content appearing in the Japanese source and should have added "necessarily" before "express" in the sentence reading "They did not express approval" (concerning TMU's action). Finally, concerning exam errors, although ideally, universities should try to "rectify the situation immediately" if serious errors are discovered in their exams, this has not always been the case (The Japan Times 2018). Moreover, these mistakes may often initially be discovered by those not associated with the juku.

The author apologizes for any confusion. He is also grateful for the opportunity to provide updates to an issue that may persist for quite some time.

References

Dunn J (2016) Wash-back and wash-forth in Japanese education: compounding the problem. Critical Thinking and Language Learning 3(1):39-49. https://www.dropbox.com/s/zaezuvf7se2mw77/CTLL\%202016.pdf?dl=0. Accessed 28 December 2018.

Guest M (2008) University exam negative wash back effect on English education. Education in Japan Community Blog. (Originally published in The Daily Yomiuri, 1 April 2008). https://educationinjapan.wordpress.com/education-system-in-japan-general/university-exam-negative-washback-effect-on-english-education/. Accessed 28 December 2018.

Ma A (2018) Japanese medical school admits rigging entrance exams in favor of men because 'women mentally mature faster.' Business Insider. https://www.businessinsider.com/japanese-medical-schools-admit-rigging-entrance-exams-to-favor--

men-2018-12. Accessed 3 January 2019.

The Japan Times (2018) A failing grade for universities' entrance exams. https:// www.japantimes.co.jp/opinion/2018/01/14/editorials/failing-grade-universities-entrance-exams/\#.XCv0VVz7TIV. Accessed 31 December 2018.

The Mainichi (2018) Entrance exam practices at 10 medical schools likely inappropriate: education ministry. https://mainichi.jp/english/articles/20181214/p2a/00m/0na/ 019000c. Accessed 3 January 2019.

The Sankei News (2019) Tōkyō idai de ippan nyūshi fusei nyūshi mondai de shigansha ōhabagan [Significant decrease in applicants taking Tokyo Medical University's general exam due to exam problem misconduct]. https://www.sankei.com/life/news/ 190202/lif1902020025-n1.html. Accessed 4 February 2019.

Tokyo Medical University (2018a) Chōsa hōkokusho [Investigation report]. https:// www.tokyo-med.ac.jp/news/media/docs/20180806houkokusyo.pdf. Accessed 16 January 2019.

Tokyo Medical University (2018b) Igakka ippan nyūshi [Department of Medicine general entrance examination]. https://www.tokyo-med.ac.jp/med/exam.html. Accessed 20 January 2019.

Published online: 14 February 2019

Reference

Wheeler (2018) The Tokyo Medical University entrance exam scandal: lessons learned. Int J Educ Integr 14:14. https://doi.org/ 10.1007/s40979-018-0039-4 